\title{
Bacteriological Contamination Detection in Water and Wastewater Samples Using OD600
}

\author{
Magdalena Domańska ${ }^{1 *}$, Kamila Hamal', Bartosz Jasionowski², \\ Janusz Lomotowski ${ }^{1}$
}

${ }^{1}$ Wroclaw University of Environmental and Life Sciences, Institute of Environmental Engineering, Wrocław, Poland

${ }^{2}$ Kielce University of Technology, Faculty of Environmental, Geomatic and Energy Engineering, Kielce

Received: 13 June 2018

Accepted: 4 September 2018

\begin{abstract}
The effectiveness of disinfection, as well as microbiological composition of water, are assessed by microbiological tests. The analysis usually takes from 24 to 48 hours. During this time the water produced at the water treatment plant has already been fed to the water supply system. In order to reduce the risk of bacteriological contamination, higher concentrations of disinfectants are maintained. Considering the fact that water supply systems use retention tanks with retention times of from 5 to 12 hours, microbiological tests should give the result in shorter time than water retention time in the water tanks. The aim of the study was to determine whether the bacterial community in static liquid medium with the control of absorbance change at $600 \mathrm{~nm}$ (OD600) can be applied as a diagnostic method at water treatment plant laboratories. The research on water and wastewater samples has shown that the duration of lag time $\lambda$ depends on the approximate amount of bacteria and the initial conditions in liquid media at the start of the experiment. It has been shown that the method can be used in the future for rapid monitoring of bacteriological contamination in the water.
\end{abstract}

Keywords: fluorescence microscopy; OD 600; UV-Vis; water quality monitoring

\section{Introduction}

There are many reasons for microbial water contamination. The most important causes are microbial infiltration into the water system or water tanks as a result of poor technical condition of the water network or equipment, the repairs, and insufficient residual concentration of disinfectant [1]. The growth of microorganisms in treated water is often a consequence

*e-mail: magdalena.domanska@upwr.edu.pl of higher contents of nutrient marked as assimilated (AOC) or biodegradable (BDOC) organic carbon introduced into the water network [2]. Microbial deterioration of water quality may also be the result of changes of the flow conditions that cause detachment of the biofilm structures from the internal pipe wall surfaces $[3,4]$. The scope of tests used to assess the microbiological composition of tap water is described in the obligatory Polish sanitary regulations [5]. The major limitation of seeding methods included in the regulation is the long waiting time for the result, usually from 24 to 48 hours, and for Legionella up to 14 days. The phenotype determination of selected bacterial strains is carried out by studying colony morphology 
using cultivation-based analysis, endospore formation, Gram staining, detection of bacterial motility on semisolid medium with 2,3,5-triphenyltetrazolium chloride (TTC), bacterial catalase and oxidase activity and acid resistance tests. The bacterial genotype can be determined by molecular methods, including, e.g., FISH (Fluorescence in situ hybridization) or polymerase chain reaction (PCR) methods and their modifications. These methods allow for shortening the time of microbiological identification $[6,7]$ but require expensive equipment, specialized reagents, and qualified staff to carry out the tests. Currently, there are no fast or inexpensive tests to effectively determine the risk of water contamination which is fed to the water supply system. In large water supply systems, the retention time of clean water in the tanks takes at least 5 hours. Therefore, microbiological tests should give the result in shorter time.

The quantity of microbial populations in batch cultures is often carried out by indirect methods. The quotient of the number of microbial cells $N$ to sample volume $V$ is called the cell density of the sample [8]:

$$
\text { Cell density }=\frac{N}{V}
$$

Studies have shown that cell density is proportional to the optical density (OD), defined as the absorbance of the test sample at the assumed wavelength:

$$
O D \sim \text { Cell density }=\frac{N}{V}
$$

Optical density is determined usually within the range of $600 \mathrm{~nm}$ as OD600 [9, 10]. Zwietering et al. [11] presented an overview of models describing the kinetics of bacterial culture growth. In the conditions of periodic bacterial culturing, characteristic phases may be distinguished. After the period of microorganism adaptation to the new environmental conditions, called lag time, there is a logarithmic increase in the number of cells in the culture (log time). In the lag time, the growth rate of bacteria is close to zero. It is assumed that in the lag time there is an adaptation of the microorganisms to the new environmental conditions by the enzymes necessary for the development of the population. The duration of the phase is characterized by $\lambda$ parameter. In the log time there is an exponential increase in the number of bacteria (biomass). The parameter describing the log time is the rate of bacterial growth. The studies of change in OD600, based on periodic culturing, are commonly used to determine the constant rate of growth in pure bacterial cultures on selected substrates. An additional advantage of the method is the result of the research confirming the high correlation between quantitative PCR and OD600 results [12].

The approximate number of bacteria can also be determined by fluorescent microscopy techniques. Currently, there is a lot of software for quantitative identification of bacteria that use the results of staining with methods such as DAPI, live/dead, FISH and fluorescence microscopy [13]. Calculations depend on counting surfaces with a specific fluorescence intensity. The analysis is usually preceded by optimization and segmentation processes to achieve the best matching of the fluorescent area to the actual surface of bacteria $[14,15]$. To date, research has focused on pure cultures rather than mixed populations, such as activated sludge flocs.

The purpose of the preliminary research was to determine whether the OD600 method is useful for monitoring bacteriological contamination in tap water, natural waters and wastewater by lag time $\lambda$.

\section{Material and Methods}

Water samples taken from the municipal water supply network, from the Odra and Oława rivers, from the lake in Mściwojów and wastewater samples from Wrocław and Oława wastewater treatment plants (WWTP) were used for the experiment. Fresh samples were mixed directly (water) or after appropriate dilution/ centrifugation (wastewater) with the medium and placed in a spectrophotometer.

\section{Dilution/Centrifugation and Medium}

In order to perform the measurement, the absorbance of the sample should not exceed 1. At the beginning, the fresh samples were not diluted (Fig.1). Next, the samples were diluted in various volume ratios with phosphate-buffered saline (PBS) (Fig. 2). In subsequent experiments, centrifugation was used at 1000, 5000, 10000 and 15000 revolutions per minute (RPM) during 3 minutes (Fig. 3). In order to avoid bacterial cell surface damage, the centrifugation force was not above $15000 \times \mathrm{g}$ [16]. Then $1 \mathrm{ml}$ of sample was mixed with $2 \mathrm{ml}$ of sterile medium LB broth (MILER) from the MERCK Co. The medium was prepared according to the manufacturer's instructions and sterilized in an autoclave.

\section{Absorbance Measurement}

Measurements of absorbance at $600 \mathrm{~nm}$ were made automatically with a predetermined time step on a Thermo Scientific UV-VIS Evolution 220 spectrophotometer using a sterile quartz cuvettes with the optical length of $1 \mathrm{~cm}$. The experiments were conducted both at room temperature and at $37^{\circ} \mathrm{C}$. The higher temperature was achieved using the Thermo Scientific Peltier Control and Cooling Unit (PCCU1). Water, as a temperature stabilizer, did not come into direct contact with the cuvette and circulated between the external heater and the single-cell holder where the cuvette was located. The device allowed for measuring 4 samples simultaneously at room temperature and only one sample at $37^{\circ} \mathrm{C}$. 


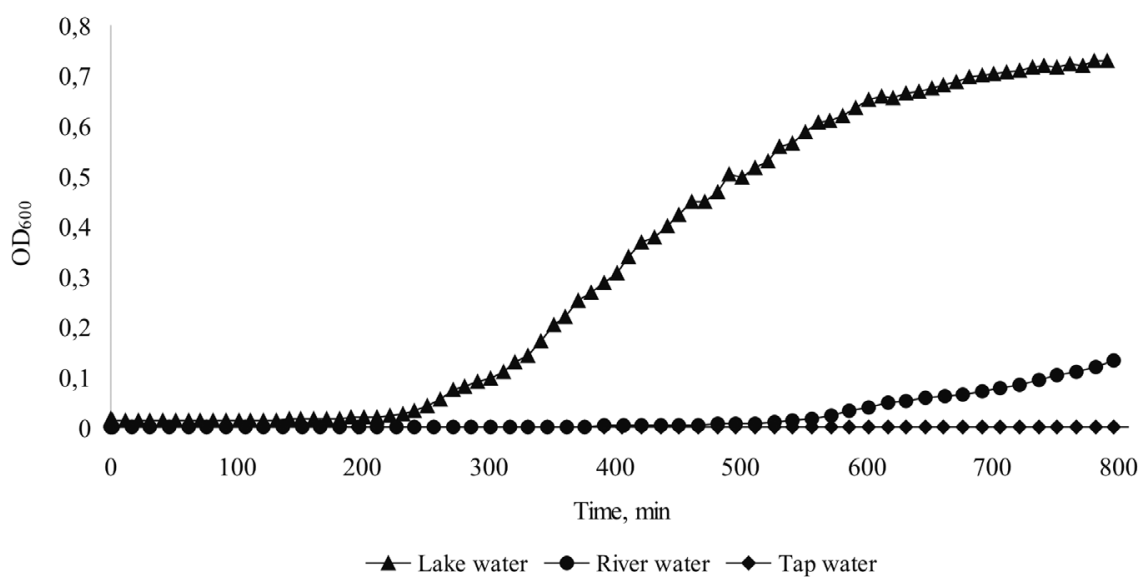

Fig. 1. Growth curves of bacteria in water samples taken from the lake in Mściwojów, the Oława River and tap water.
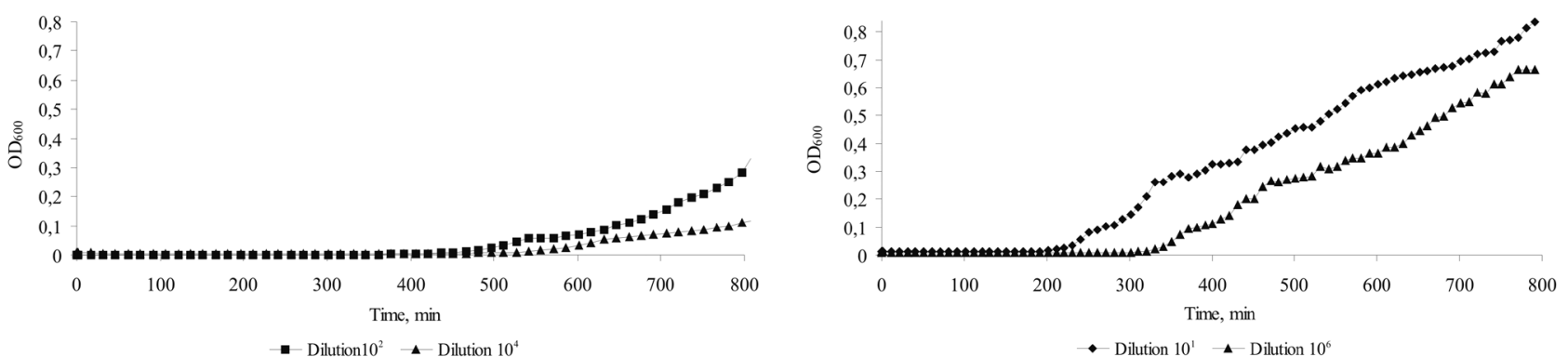

Fig. 2. Growth curves of bacteria in water samples taken from the Odra River (left) and a sample of activated sludge (right) in various dilutions.

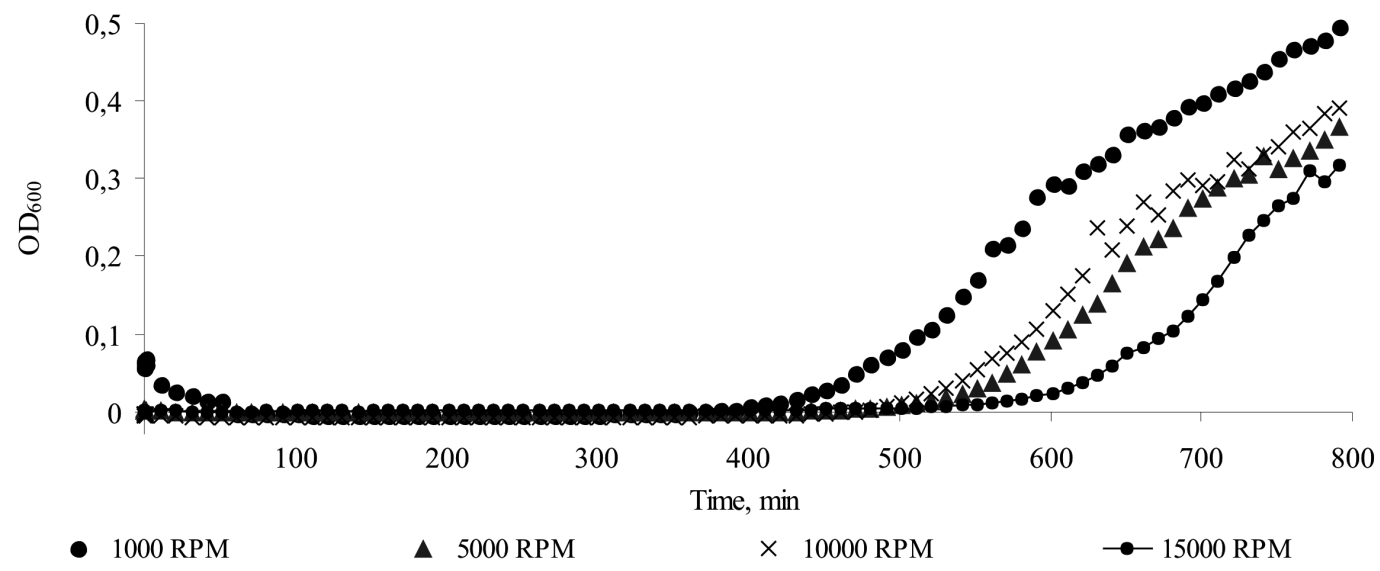

Fig. 3. Growth curve of bacteria in the sample of activated sludge from Oława WWTP at various RPMs.

\section{Evaluating the Microbial Presence}

The presence of microorganisms in tap water was detected with a culture-based method on Petri plates with agar (catalogue nr 5040) from Sigma-Aldrich. Studies on the presence of bacteria in wastewater and natural waters using the live/dead reagent of Thermo Fisher (No. L7007) on a Nikon Elicpse Ni-E C2 microscope were conducted. A mixture of propidium iodide (which penetrates only damaged or dead cells) and SYTO 9 (which dyes living cells) was added to the $1 \mathrm{ml}$ centrifuged sample. After a contact time of 15 minutes, $5 \mu$ l of the solution was placed on the slide. Additionally, BacLight mounting oil (from Life Technologies) was added on the dried sample to prevent it from fading. The analysis was conducted using the CFI Plan Apo 60x oil objective and the B-2A EX 450-490, DM 505, BA $520 \mathrm{~nm}$ filter. Quantification of 


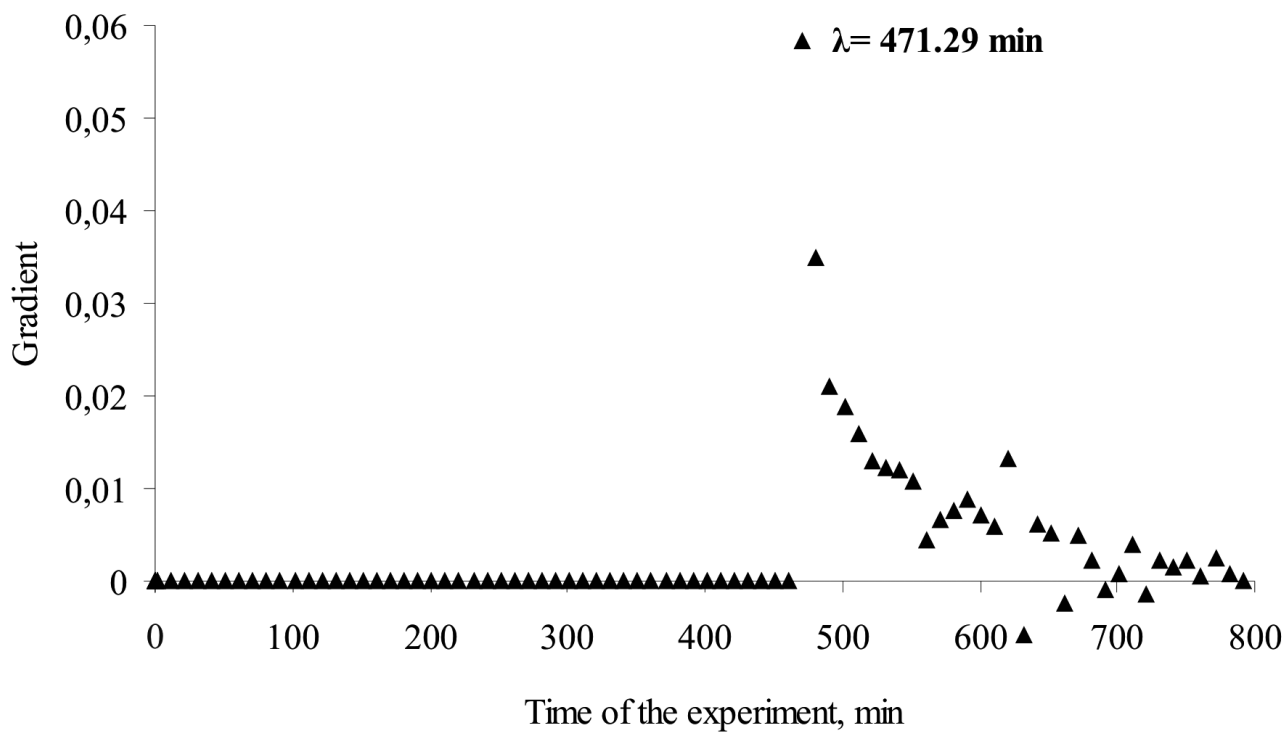

Fig. 4. Gradient values calculated from Formula 3 to determine the duration of lag time $\lambda$.

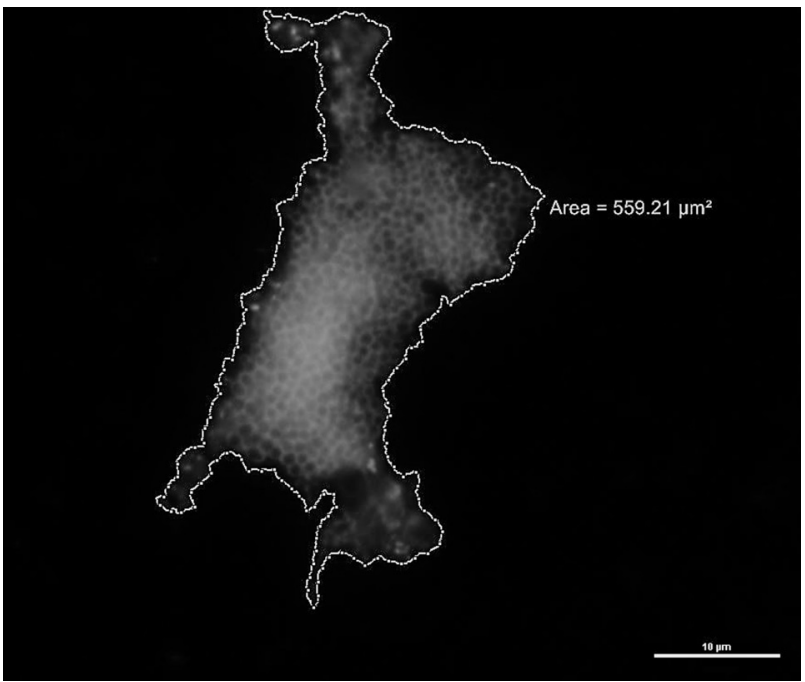

Fig. 5. Fluorescent area of microorganisms from Oława WWTP sample (at $5000 \mathrm{RPM}$ ); bar $10 \mu \mathrm{m}$. microorganisms was performed by direct counting of fluorescent areas from 20 random fields in each well using Nis-Elements AR Analysis 4.30 (Fig. 5). After that, the fluorescent areas of the individual fields at different RPMs were calculated and presented in Fig. 6.

\section{Results and Discussion}

Fig. 1 shows growth curves of microorganisms in water samples from the lake in Mściwojów, the Oława River, and tap water. No change in OD 600 in the tap water sample was observed. The culture-based method confirmed the absence of bacterial colonies. In the research conducted using surface water, the typical kinetic curve of OD600 was observed. The duration of lag time $\lambda$ was much shorter for the water taken from the reservoir than the water from the river (Fig. 1). Studies on wastewater and water from the river have

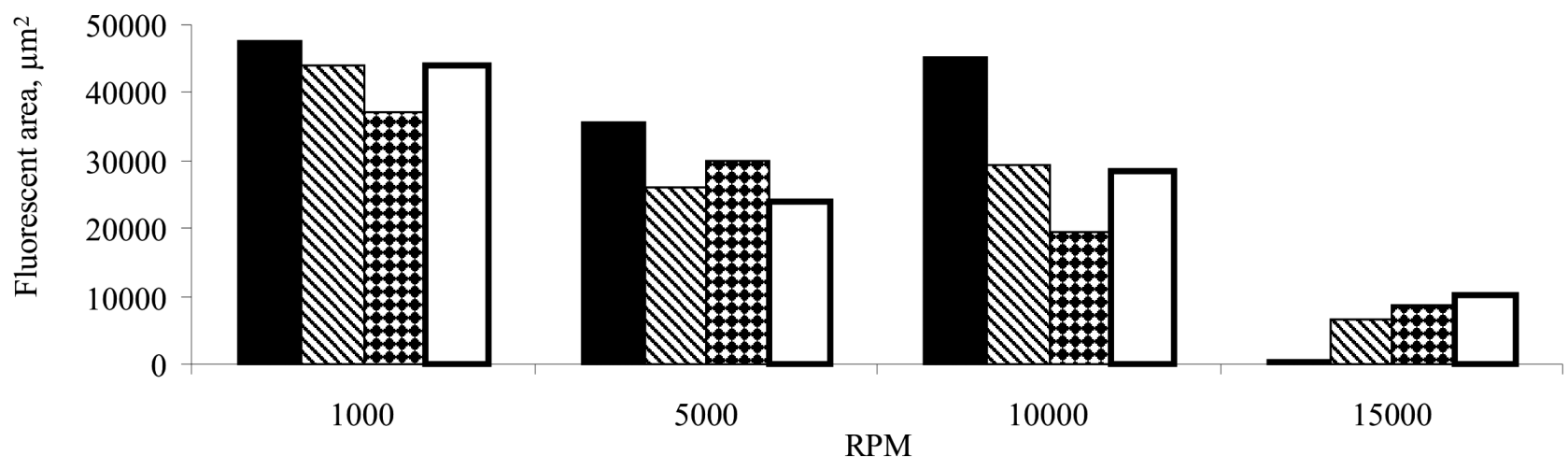

$\mathrm{Nr} 1 \mathrm{~N} \mathrm{Nr} \mathrm{Nr} 3 \mathrm{Dr} 4$

Fig. 6. Amount of fluorescent areas showing the presence of microorganisms in the samples taken from Oława WWTP depending on RPM (Nos. 1-4 represent the collected samples). 
shown that in higher dilution of the samples the duration of lag time $\lambda$ increases (Fig. 2). Preliminary studies have shown that the duration of lag time $\lambda$ probably depends on the level of microbial contamination at the start of the experiment.

In the following tests, a sample centrifugation was used to remove some of the impurities from the activated sludge and to check the effect of the microbial contamination on the lag time. Centrifugation requires neither such precision, nor additional reagents, nor time consumption. Four experiments $(\mathrm{Nr} \mathrm{1-4)}$ on the samples from Oława WWTP collected weekly during the summer season were carried out.

The result of one of them is shown in Fig. 3, which displays the increase of the duration of lag time along with the RPM. It was noticed especially between 1000 and 15000 RPM. There were no considerable differences between the revolutions of 5000 and 10000 per minute. This result was confirm in subsequent experiments.

Then the duration of the lag time was determined. The gradient was calculated from Formula 3:

Gradient $=\frac{\ln O D_{600(n+1)}-\ln O D_{600(n)}}{\left(t_{n+1}-t_{n}\right)}, \min ^{-1}$

where:

In $O D_{600(n+1, n)}$ - natural logarithm of optical density at $600 \mathrm{~nm}$ of absorbance for the subsequent steps of the experiment [-];

$t_{(n+1, n)}$ - time for the subsequent steps of the experiment [min], reaches a maximum value which reflects the end of lag time $\lambda$ (Fig. 4).

At the same time, absorbance measurements and microscopic analysis were carried out. One sample with the medium after centrifugation was placed in the spectrophotometer and the other was mixed with the live/dead reagent to determine the number of microorganisms. During the quantitative analysis of bacteria, the "area" function in Nis-Elements AR Analysis 4.30 was used to mark the areas of suitable intensity of green light. There were no optimization or segmentation steps using the binary image as it is usually used for image analysis [14, 15], mainly due to the presence of extensive structures such as activated sludge flocs. In that case, a precise approach to the image analysis does not bring much to the result and is really time-consuming. The example of the area of microorganisms is shown in Fig. 5. Quantification of microbes was performed by direct counting of 20 random fields in each well using fluorescence microscopy. Then the areas were calculated and shown in Fig. 6.

During analysis, the pictures were similar to each other and no difference in the samples centrifuged from 1000 to 10000 RPM was observed. In the sample centrifuged at 15000 RPM, there were significantly fewer numbers of bacteria. Only then did the calculated areas show differences in the amount of bacteria in each sample (Fig. 6).

The relationship between duration of lag time $\lambda$ and fluorescent areas of microorganisms obtained from 20 random pictures is shown in Fig. 7. The relationship between the parameters followed the linear trend with $\mathrm{R}^{2}=0,3578$. Certain data points were out of $95 \%$ confidence interval (Conf. Int.), but showed the correlation between different RPMs.

Numerous authors indicated that the duration of lag time $\lambda$ depends not only on the initial number of bacteria but also on the stress factors such as $\mathrm{pH}$ and

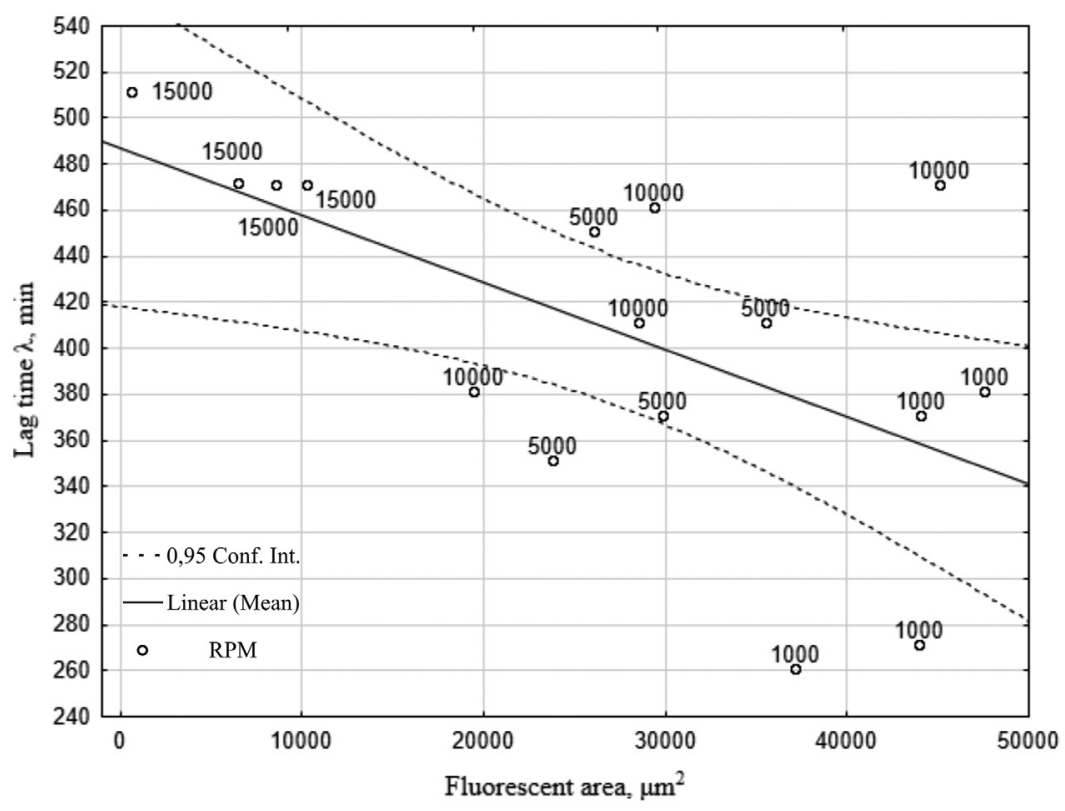

Fig. 7. Relationship between the duration of lag time $\lambda$ of microorganisms from wastewater samples centrifuged at different RPMs and fluorescent areas of microorganisms obtained from 20 random pictures; confidence interval determined at $95 \%$. 


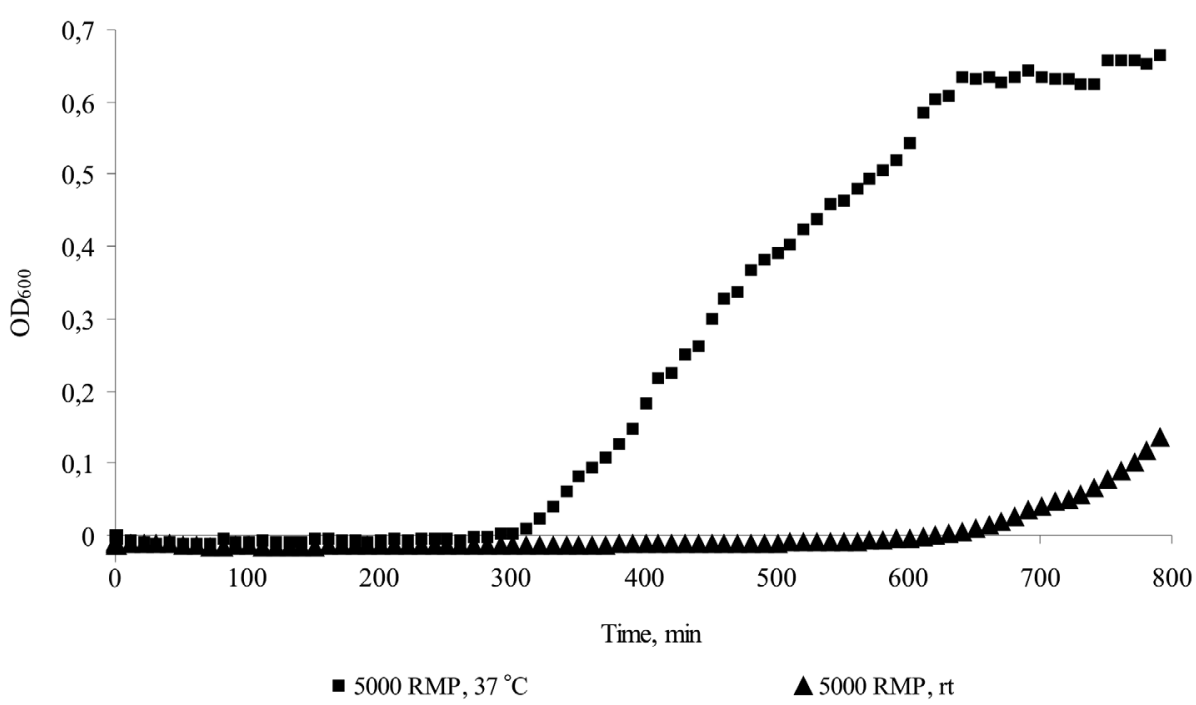

Fig. 8. Growth curve of bacteria in a sample of activated sludge at room temperature (rt) and $37^{\circ} \mathrm{C}$, or at various RPMs.

temperature [17]. The obtained results confirmed that the extended lag time $\lambda$ is associated with fewer microorganisms. Fig. 7 shows the differences between 1000 and 15000 RPM. There is no significant difference between samples centrifuged at 5000 and 1000 RPM. Additional analysis should be carried out in order to achieve better fitting.

Further experiments were carried out on the activated sludge sample to verify the influence of temperature on lag time and the shape of growth curve. Centrifuging at $5000 \mathrm{RPM}$ and room temperature as well as $37^{\circ} \mathrm{C}$ were applied. The lag time was almost twice shorter for samples incubated at $37^{\circ} \mathrm{C}$. The lag time was 631.3 and 301.3 minutes for room temperature and for $37^{\circ} \mathrm{C}$, respectively. Fig. 8 shows that the higher temperature shortens the lag time, which is confirmed by Sant'Ana et al. [18].

Research available in the literature has explained the duration of lag time $\lambda$ to a certain extent. The shape of the bacterial growth curve depends on various factors, e.g., bacterial substrates and storage cell compounds inside cells, which affects competition between microorganisms $[19,20]$. The research has shown that the duration of lag time $\lambda$ depends on the microbial contamination in liquid media at the start of the experiment. The approximate number of bacteria was also confirmed with fluorescence microscopy. Furthermore, the temperature increase shortened the duration of lag time $\lambda$.

The methodology for the modeling of microbial growth in pure bacterial cultures is available in the literature. The studies conducted on mixed populations of bacteria from rivers, lakes or sewage treatment plants have shown that the duration of lag time can be used to estimate microbial contamination in the waters. In the case of sewage, the use of the OD600 method makes it difficult to separate impurities from bacteria before the absorbance measure. For this reason, the determination of lag time obtained with the OD600 method for wastewater samples is not so precise.

The presented method, considering the low cost of equipment and the simplicity of research procedures, may be used in the future as a fast way to monitor the quality of water feeding the water supply network. It is necessary to continue the studies with other liquid media and experimental conditions.

\section{Conclusions}

The methodology for modeling microbial growth in pure bacterial cultures is available in the literature. Studies conducted on mixed populations of bacteria, which is a novelty of this research, have shown that the duration of lag time can be used to estimate microbial contamination in water.

Research available in the literature has explained the duration of lag time $\lambda$ to a certain extent. The shape of the bacterial growth curve depends on various factors, e.g., bacterial substrates and storage cell compounds inside cells, which affects competition between microorganisms $[19,20]$. The research has shown that the duration of lag time $\lambda$ depends on the microbial contamination in liquid media at the start of the experiment. The approximate number of bacteria was also confirmed with fluorescence microscopy. Furthermore, the temperature increase shortened the duration of lag time $\lambda$.

The presented method considering low in cost for equipment, and the simplicity of research procedures may be used in the future as a fast way to monitor the quality of water feeding the water supply network. It is necessary to continue the studies with other liquid media and experimental conditions. 


\section{Conflict of Interest}

The authors declare no conflict of interest.

\section{References}

1. DOMAŃSKA M., ŁOMOTOWSKI J. Badania nad szybkością zaniku chloru i dwutlenku chloru w wodzie w sieci wodociągowej (Rate of Chlorine and Chlorine Dioxide Decay in the Water-pipe Network). Ochrona Środowiska, 31 (4), 47, 2009 [In Polish].

2. ESCOBAR I.C., RANDALL A. A. Assimilable organic carbon (AOC) and biodegradable dissolved organic carbon (BDOC): complementary measurements. Water Research, 35 (18), 4444, 2001.

3. ALBERTA M., HIJNENA W., VAN VOSSENA J., BLOKKERA M. Modelling bacterial biomass non chlorinated drinking water distribution system. Procedia Engineering, 186, 127, 2017.

4. FISH K., OSBORN A.M., BOXALL J.B. Biofilm structures (EPS and bacterial communities) in drinking water distribution systems are conditioned by hydraulics and influence discoloration. Science of the Total Environment, 593-594, 571, 2017.

5. Regulation of the Minister of Health of 13 November 2015 on the quality of water intended for human consumption (Journal of Laws item 1989), Poland [In Polish].

6. NIELSEN P.H., DAIMS H., LEMMER H. FISH Handbook for Biological Wastewater Treatment, Identification and quantification of microorganisms in activated sludge and biofilms by FISH. IWA Publishing, London, 2009.

7. DOMAŃSKA M., KUHN R., ŁOMOTOWSKI J., STAŃCZYK E. FISH method for identification of microbes in wastewater distribution systems. EPE Journal, 40 (3), 151, 2014.

8. WIDDEL F., Theory and measurement of bacterial growth, Grundpraktikum Mikrobiologie, Sem. 4, (B.Sc.) Universität Bremen, 1, 2010.

9. HOMMES N.G., SAYAVEDRA-SOTO L.A., ARP D.J. Chemolithoorganotrophic Growth of Nitrosomonas europaea on Fructose. Journal of Bacteriology, 185 (23), 6809, 2003.

10. DUEDU K.O., FRENCH C.E. Two-colour fluorescence fluorimetric analysis for direct quantification of bacteria and its application in monitoring bacterial growth in cellulose degradation systems. Journal of Microbiological Methods, 135, 85, 2017.

11. ZWIETERING M.H., JONGENBURGER I., ROMBOUTS F.M., VAN'T RIET K., Modeling of Bacterial Growth Curve. Applied and Environmental Microbiology, 56 (6), $1875, \mathbf{1 9 9 0}$

12. SAVICHTCHEVA O., JORIS B., WILMOTTE A., CALUSINSKA M. Novel FISH and quantitative PCR protocols to monitor artificial consortia composed of different hydrogrn-producing Clostridium spp. International Journal of Hydrogen Energy, 36 (13), 7530, 2011.

13. WIESMANN V., FRANZ D., HELD C., MUNZENMAYER C., PALMISANO R., WITTENBERG T. Review of free software tools for image analysis of fluorescence cell micrographs, Journal of Microscopy, 257 (1), 39, 2015.

14. FONTENETE S., CARVALHO D., LOURENÇO A, GUIMARÃES N., MADUREIRA P., FIGUEIREDO C., AZEVEDO N.F. FISHji: New ImageJ macros for the quantification of fluorescence in epifluorescence images. Biochemical Engineering Journal, 112, 61, 2016.

15. MESQUITA D.P., AMARAL A.L., FERREIRA E.C. Estimation of effluent quality parameters from an activated sludge system using quantitative image analysis. Chemical Engineering Journal, 285, 348, 2016.

16. PETERSON W., SHARMA P.K., VAN DER MEI H.C., BUSSCHER H.J. Bacterial Cell Surface Damage Due to Centrifugal Compaction Brandon, Applied and Environmental Microbiology, 78 (1), 120, 2012.

17. SWINNEN I.A.M., BERNAERTS K., DENS E.J.J., GEERAERD A.H., VAN IMPE J.F. Predictive modeling of the microbial lag phase: a review. International Journal of Food Microbiology, 94, 137, 2004.

18. SANT'ANA A.S, FRANCO B.D.G.M., SCHAFFNER D.W. Modeling the growth rate and lag time of different strains of Salmonella enteric and Listeria monocytogenes in ready-to-eat lettuce. Food Microbiology, 30, 267, 2012.

19. BARANYI J. Modelling and parameter estimation of bacterial growth with distributed lag time. PhD thesis, Doctoral School of Informatics University of Szeged, Hungary, 2010.

20. LOU I., DE LOS REYES III F.L. Substrate Uptake Tests and Quantitative FISH Show Differences in Kinetic Growth of Bulking and Non-Bulking Activated Sludge. Biotechnology and Bioengineering, 92 (6), 729, 2005. 